\title{
Inhibition of aspirin-induced bronchoconstriction by sodium cromoglycate inhalation
}

\author{
N. A. MARTELLI AND G. USANDIVARAS \\ From the Centro de Rehabilitacion Respiratoria 'Maria Ferrer', Finochietto 849, Buenos Aires, \\ Argentina 1272
}

\begin{abstract}
Martelli, N. A., and Usandivaras, G. (1977). Thorax, 32, 684-690. Inhibition of aspirin-induced bronchoconstriction by sodium cromoglycate inhalation. Five patients with asthma and severe aspirin hypersensitivity were challenged on separate days with increasing doses of aspirin given by mouth, starting with $5 \mathrm{mg}$, until a reduction in $\mathrm{FEV}_{1}$ greater than $15 \%$ was obtained. Sodium cromoglycate in doses of $20-40 \mathrm{mg}$ inhibited the bronchoconstrictive reaction not only when inhaled before the challenge but also after it, at a time when progressive reduction in $\mathrm{FEV}_{1}$ values was taking place. According to these results, it seems reasonable to postulate sequential mast cell degranulation and liberation of mediators of anaphylaxis as the mechanism through which aspirin induces bronchoconstriction in aspirin-sensitive asthmatics. The differences between bronchial provocation tests and oral challenge with aspirin are stressed.
\end{abstract}

The syndrome of increased airways resistance in aspirin-sensitive asthmatics after aspirin ingestion (Samter and Beers, 1967) is characterised by the onset of watery rhinorrhoea followed within a few minutes by bronchoconstriction and wheezing. Symptoms may appear almost immediately after ingestion or be delayed up to two hours. This entity occurs especially in middle-aged women and is frequently associated with vasomotor rhinitis and nasal polyps. The same asthmatic attacks can be precipitated by a number of aspirin-like drugs: aminopyrine, indomethacin (Samter and Beers, 1968), phenylbutazone, flufenamic acid, mephenamic acid (Szczeklik et al., 1975), paracetamol, and dextropropoxyphene (Smith, 1971). Although several hypotheses have been put forward, pathogenesis remains obscure.

This paper reports the effects of sodium cromoglycate $\left(\right.$ Intal $\left._{R}\right)$ on aspirin-induced bronchoconstriction in five patients with bronchial asthma.

\section{Patients and methods}

Five patients, four women aged 17, 42, 49, and 62 years and one man aged 57, were studied. All had bronchial asthma with a duration ranging from 2 to 17 (mean 9.4) years. All gave a history of severe asthmatic attacks after taking one tablet $(500 \mathrm{mg})$ of aspirin. All reacted to prick tests with at least two inhalant allergens and had either blood eosinophilia of over $500 / \mathrm{mm}^{3}\left(0.5 \times 10^{9} / \mathrm{l}\right)$ or eosinophils in sputum or nasal secretions. Four had nasal polyps and three gave a history of family allergy. In one patient the first attack of asthma had coincided with taking an aspirin tablet, but in the rest hypersensitivity had developed after the onset of asthma. Although all patients had received steroids for brief periods, in no case was the control of asthma a serious problem.

\section{CHALLENGE TESTS}

All antiasthmatic drugs were stopped at least 12 hours before each study. None of the patients was receiving either sodium cromoglycate or steroids. The forced expiratory volume in one second $\left(\mathrm{FEV}_{1}\right)$ was recorded on a dry bellows spirometer (Vitalograph) with the patient in the sitting position. Patients were challenged with aspirin given by mouth in capsules in doses ranging from 5 to $100 \mathrm{mg}$. Lactose $(100 \mathrm{mg})$ was used as a placebo and administered in identical capsules. The challenge tests were done in the morning after a light breakfast. After establishing baseline values for $\mathrm{FEV}_{1}$ a capsule of either aspirin or placebo was ingested. FEV 1 (best of two measurements) was then recorded every 15 or 30 minutes for at least three hours. Observation for longer periods was reserved either for patients showing a fall in FEV 1 to less than 1 litre or when it was desired to follow the natural course of the 
bronchoconstrictive reaction or its modification by sodium cromoglycate. Only one dose of aspirin was administered on any one day and this was increased on successive days until a fall in $\mathrm{FEV}_{1}$ greater than $15 \%$ from control values was obtained. Subsequently, the patients were challenged with the particular dose.

Sodium cromoglycate (either one or two $20-\mathrm{mg}$ capsules) was inhaled using a Spinhaler in three different situations-Procedure A: as a single dose 15 minutes before the challenge ( 3 cases); Procedure B: 15 minutes before the challenge and 15 minutes before the time when the $\mathrm{FEV}_{1}$ was expected to fall, as judged from a previous challenge (4 cases); and Procedure $C$ : as a single dose at a time when the challenge had produced a reduction in $\mathrm{FEV}_{1}$ of at least $20 \%$ of control values and a considerable fall was still expected to occur as indicated by previous challenges ( 3 cases).

Inhaled $\beta_{2}$ adrenergic drugs (fenoterol, ${ }^{1}$ salbutamol) or intravenous injection of aminophylline and/ or hydrocortisone hemisuccinate were administered when patients complained of disturbing dyspnoea or severe tightness in the chest.

The patients were told that they would be given drugs which might induce severe bronchoconstriction but the kind of drug was unknown to them. Full consent was obtained from all patients.

\section{Results}

Oral ingestion of aspirin produced in all patients a reaction characterised by watery rhinorrhoea followed by audible wheezing and an asthma attack. Sometimes only the first symptom was present.

A fall in FEV $_{1}$ greater than $15 \%$ of control values was observed with doses of aspirin ranging from 20 to $100 \mathrm{mg}$. The time interval between ingestion of the drug and decrease in $\mathrm{FEV}_{1}$ ranged between 15 and 105 minutes. With increasing dosage there was a progressive shortening of this time interval, and $\mathrm{FEV}_{1}$ curves showed steeper slopes and lower values, indicating that the reaction was dose-dependent (Fig. 1). Once bronchoconstriction started there was a steady decline in $F E V_{1}$, reaching its lowest value in 1-2 hours. This commonly took place between the second and the fourth hour after challenge and was followed in some patients by a very slow recovery phase, the $\mathrm{FEV}_{1}$ being $40 \%$ under control values at 9 hours in one case and $20 \%$ after 26 hours in another (Fig. 2). The degree of fall in the FEV 1 and the time relationship of the fall after challenge with a given dose of aspirin on successive days was found to be remarkably similar for each individual but different from case to case.

${ }^{1} 1$ - (3,5 - Dihydroxyphenyl) - 2 -[11 - (4 - hydroxybenzy]) - ethyl]-amino]ethanol bromhydrate (BEROTEC $($ B) Boehringer, Ingelheim
PROCEDURE A

The results on three patients are shown in Fig. 3. A single dose of sodium cromoglycate inhaled before the challenge with aspirin delayed the onset of bronchoconstriction for 45 minutes in one patient and for 75 minutes in the remaining two. In two patients the reduction in $\mathrm{FEV}_{1}$ was of lesser degree (400 and $800 \mathrm{ml}$ ) after sodium cromoglycate and in the third it was of similar severity.

\section{PROCEDURE B}

Four patients were studied by this procedure. Inhalation of sodium cromoglycate before the

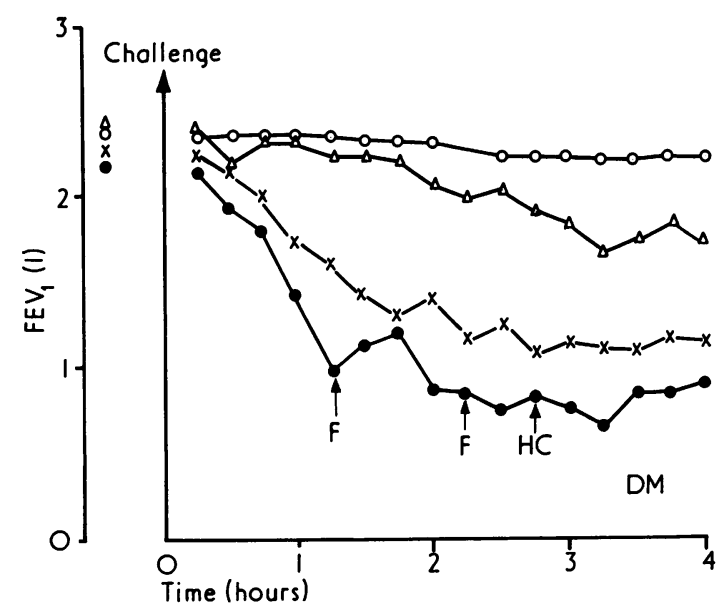

Fig. 1 Oral challenge with aspirin. Changes in FEV with increasing dosage in one patient: $\bigcirc-O$ placebo, $\triangle \longrightarrow \triangle 20 \mathrm{mg}, \times \longrightarrow \times 40 \mathrm{mg}, \longrightarrow 100 \mathrm{mg}$. $F=$ fenoterol 3 puffs, $H C=$ hydrocortisone $0.5 \mathrm{~g}$.

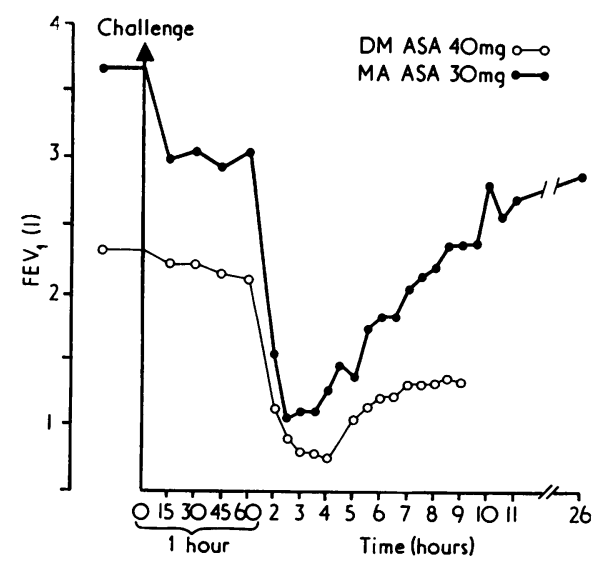

Fig. 2 Oral challenge with aspirin $(A S A)$ in patients $D M$ and $M A$. Natural course of FEV $V_{1}$ changes. 

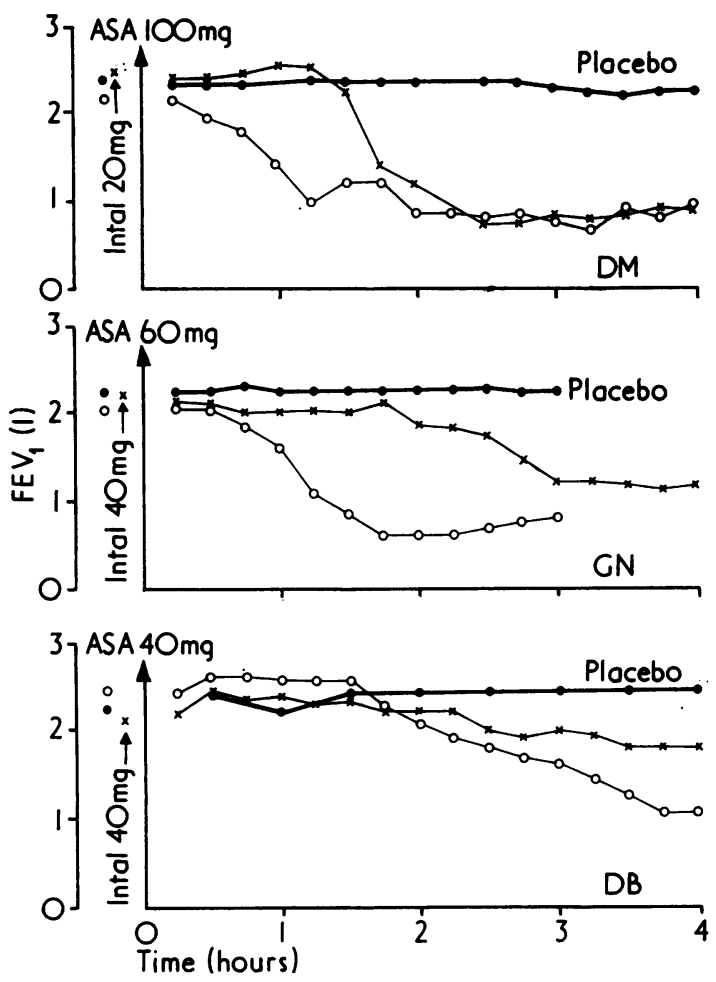

Fig. 3 Procedure A in three patients: $\bullet-\longrightarrow$ placebo, $\bigcirc-O$ oral challenge with aspirin $(A S A), \times-\times$ oral challenge with aspirin + sodium cromoglycate (Intal) inhaled before the challenge.

challenge and before the expected fall in $\mathrm{FEV}_{1}$ delayed the onset of bronchoconstriction for three hours in one patient (Fig. 4) and for four hours in another (Fig. 5). In both cases the reduction in FEV was greater than values obtained during aspirin challenge alone, and bronchodilators were necessary to finish the test. The remaining two patients were followed for four hours after the challenge. No modification in $\mathrm{FEV}_{1}$ was observed during that period and no untoward effects were noticed by the patients during the rest of the day.

\section{PROCEDURE C}

Three cases were examined by this procedure. The administration of sodium cromoglycate approximately half-way between control and maximum expected fall in $\mathrm{FEV}_{1}$ was followed by an immediate inhibition of the bronchoconstriction and subsequent increase in $\mathrm{FEV}_{1}$. Patient MA (Fig. 5) showed a maximum increase in FEV 1 of $300 \mathrm{ml} 30$ minutes after sodium cromoglycate inhalation followed by a 30 -minute plateau. Thereafter there was a pronounced fall in $\mathrm{FEV}_{1}$ and bronchodilators were needed. In patient BD the $\mathrm{FEV}_{1}$ increased by $600 \mathrm{ml} 1$ hour and 45 minutes after sodium cromoglycate inhalation but decreased later by $300 \mathrm{ml}$ and thereafter no further change was observed (Fig. 6). In patient $S M$ the $F E V_{1}$, which had fallen from a control level of 2.3 to 1.8 litres, showed a steady increase, starting 15 minutes after the sodium cromoglycate, and two hours later had risen by $450 \mathrm{ml}$ to

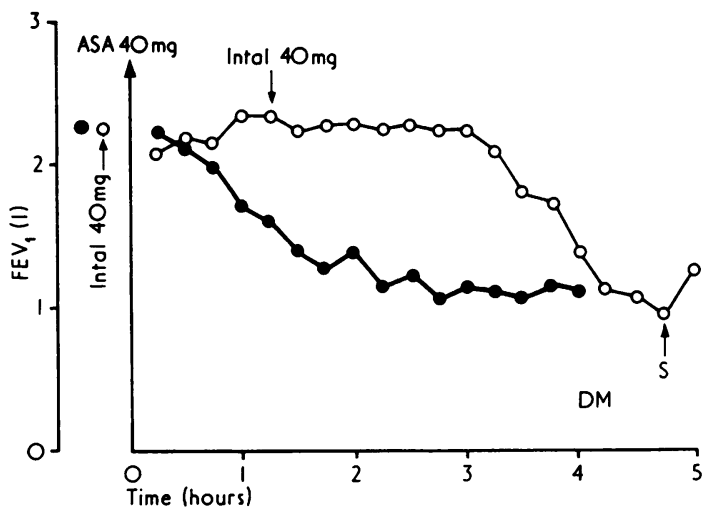

Fig. 4 Procedure $B$ in one patient: $\bullet-\longrightarrow$ oral challenge with aspirin $(A S A), \bigcirc-\bigcirc$ oral challenge with aspirin + sodium cromoglycate (Intal) inhaled before the challenge and 15 minutes before expected fall in $F E V_{1}$ as judged from a previous challenge. $S=$ salbutamol 3 puffs.

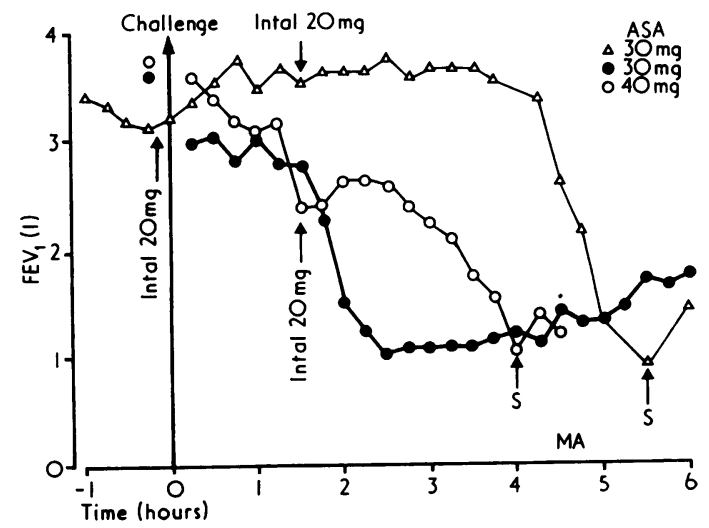

Fig. 5 Procedures $B$ and $C$ in one patient: $-\longrightarrow$ oral challenge with aspirin $(A S A), \triangle \longrightarrow \triangle$ oral challenge with aspirin + sodium cromoglycate (Intal) inhaled before and after the challenge (procedure $B), \bigcirc-\bigcirc$ oral challenge with aspirin + sodium cromoglycate inhaled when bronchoconstriction is in progress (procedure C). $S=$ salbutamol 3 puffs. 


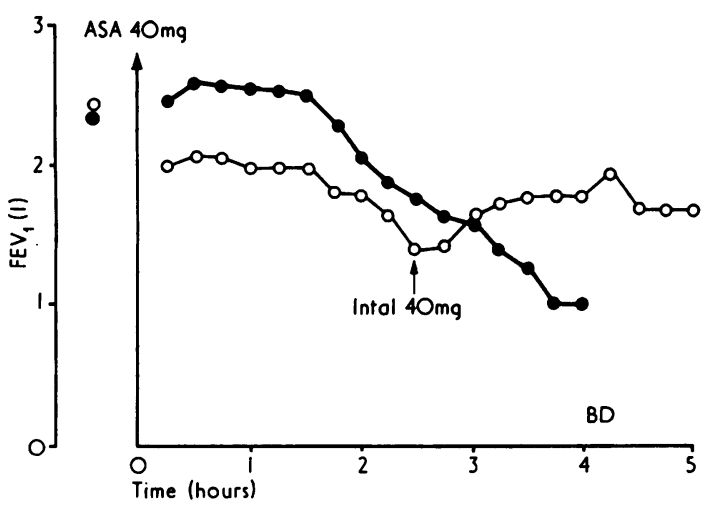

Fig. 6 Oral challenge with aspirin $(A S A) \bullet-\bullet$, and oral challenge with aspirin + sodium cromoglycate

(Intal) $\bigcirc-\bigcirc$ inhaled during progressive

bronchoconstriction (procedure $C$ ).

only $50 \mathrm{ml}$ below the control value and the test was finished five hours after challenge without further change in $\mathrm{FEV}_{\mathbf{1}}$.

Placebo challenge produced neither rhinitis nor changes in $\mathrm{FEV}_{1}$ in any patient.

\section{Discussion}

We have shown that sodium cromoglycate effectively inhibits aspirin-induced bronchoconstriction in aspirin-sensitive asthmatics whether administered before the challenge or once there is considerable bronchoconstriction in progress. It would follow that an analysis of the mode of action of sodium cromoglycate might clarify the mechanism by which aspirin induces bronchoconstriction.

Sodium cromoglycate inhibits immediate-type hypersensitivity reactions to antigen (type I reaction mediated by specific reaginic IgE antibodies) both in vivo and in vitro (Cox and Altounyan, 1970). In man, prior inhalation of sodium cromoglycate inhibits the immediate reaginic bronchoconstriction produced by inhalation challenge with allergen. It also proved effective in giving protection against inhalation challenge producing dual bronchoconstrictive reactions (immediate type I and late type III precipitin-mediated reaction) or in some cases of isolated late reactions (Pepys and Hutchcroft, 1975). Sodium cromoglycate has neither bronchodilating nor anti-inflammatory properties (Cox and Altounyan, 1970) and does not antagonise the action of mediators of anaphylaxis (Cox, 1971). It has been shown in asthmatics that prior inhalation of sodium cromoglycate fails to protect against inhaled histamine (Kang et al., 1976) or prostaglandin (PG) $\mathrm{F}_{2} \alpha$-induced bronchoconstriction (Patel, 1975). It has been shown experimentally that sodium cromoglycate inhibits the degranulation of mast cells of IgE-dependent immediate hypersensitivity reactions, thus blocking the release of the mediators of anaphylaxis (histamine, slow reacting substance of anaphylaxis (SRS-A)) (Cox, 1971). Studies in rats have shown that sodium cromoglycate does not affect the fixation of reaginic antibodies to the cell surface or the interaction of antigen with fixed cell antibody (Cox, 1971). Hence this drug probably acts on the biochemical events following antigen-antibody interaction on the cell surface. It has been proposed that sodium cromoglycate inhibits antigen-induced degranulation by interfering with calcium transport across the mast cell membrane (Foreman and Garland, 1976) or increasing cyclic 3', 5'-AMP by inhibiting phosphodiesterase (Lavin et al., 1976). But the protective action of sodium cromoglycate is not restricted to allergic challenge alone. It has been shown that prior inhalation of sodium cromoglycate partially protects against exercise-induced bronchoconstriction (Davies, 1968) or bronchoconstriction due to repeated forced vital capacity manoeuvres (Roncoroni et al., 1975). It also inhibits mast cell degranulation and release of mediators caused by compound $48 / 80$ or by phospholipase A, two situations in which there is no direct involvement of antigen antibody interaction (Cox, 1971). Since the principal action of sodium cromoglycate is to inhibit allergic or, in certain circumstances, non-allergic mast cell degranulation, and since it affords protection against aspirin-induced bronchoconstriction in aspirin-sensitive asthmatics it seems reasonable to postulate that aspirin induces bronchoconstriction through mast cell degranulation and release of mediators of anaphylaxis. The question arises whether this reaction is immunological (antibody mediated) or directly caused by the action of aspirin. Apart from occurring in asthmatics, its rather explosive nature resembling an anaphylactic reaction (when sufficient dose of aspirin is given), and its inhibition by sodium cromoglycate, there are no other reasons to indicate that this reaction is immunological (IgE mediated). On the other hand, there are observations which support a non-immunological pathogenesis. Skin tests with aspirin in sensitive patients are negative (Girard et al., 1969; Schlumberger et al., 1974). Serum IgE levels have been within normal limits, and efforts to transfer the symptoms to monkeys with serum from aspirin sensitive patients and subsequent challenge with aspirin proved unsuccessful (Vatanasuk et al., 1971; Schlumberger et al., 1974).

A second point of interest is the substantial difference between inhalation challenge and oral challenge with aspirin. In bronchial provocation 
tests a certain amount of antigen is delivered to the bronchial tree in a few breaths or minutes. The rapid interaction between antigen and mast cell bound IgE antibody causes bronchoconstriction which reaches its peak in approximately 15 minutes and subsides in two hours. When sodium cromoglycate is given after the challenge it affords little or no protection (Cox and Altounyan, 1970) because interaction between antigen and antibody has already occurred and degranulation of affected mast cells is probably completed. This reaction is dose dependent. On the other hand, aspirin has to be absorbed from the gut before reaching the lung via the circulation, and this delays the onset of the reaction which is also dose dependent. It has been shown that when aspirin is ingested in small doses $(250 \mathrm{mg})$ the half-life of salicylate elimination is 2.9 hours (Levy, 1965). We have not been able to find reports about the pharmacokinetics of smaller doses of aspirin such as the ones we have given, but even assuming a shorter half-life there should be measurable levels of serum salicylate in our experiments at the end of the third or fourth hour. This results in a unique source of antigen continously challenging the lungs for some hours as opposed to the short exposure in inhalation challenge, and is reflected in the time-course of the reaction and probably in its response to sodium cromoglycate. Sodium cromoglycate is not effective when given after antigen inhalation. Furthermore, it does not work if the patient is wheezing and therefore should not be used in the treatment of acute asthma attacks (Kolotkyn et al., 1974). Aspirin-induced bronchoconstriction seems to be an exception to the general rule and since sodium cromoglycate is effective after the challenge, mast cell degranulation in this case must proceed in a sequential fashion. It is possible, as has been suggested, that there may be different populations of mast cells (Beaven, 1976), and it is conceivable that these cells might show differences in sensitivity to aspirin and this, coupled with sequential activation, could explain the prolonged time-course of the reaction and the inhibition of progressive bronchoconstriction by sodium cromoglycate. It is of interest that the duration of action of sodium cromoglycate should last in some cases for rather brief periods according to usual standards (one hour or less). This seemed to be related to the dosage of aspirin and sodium cromoglycate and to the degree of hypersensitivity of the patient.

The evidence presented in this paper points to mast cell degranulation as the final link of a chain which starts with aspirin ingestion. Unfortunately, we know little about what happens in between. After the ingestion of $650 \mathrm{mg}$ of aspirin, aspirin plasma levels rise sharply, reach a peak between 10 and 20 minutes, and then decline rapidly, only small amounts persisting after two hours (Rowland et al., 1972). On the other hand, the level of salicylic acid in plasma rises sharply and eventually exceeds that of aspirin to reach a plateau at 60 minutes, which lasts for three or more hours (Rowland et al., 1972; McDonald et al., 1972). Since bronchoconstriction in procedure B appeared three or more hours after challenge, at a time when serum aspirin levels should be negligible, it seems highly unlikely that aspirin itself is the responsible antigen. On the other hand, serum salicylate levels during aspirin challenge are similar in patients with and without sensitivity to aspirin (McDonald et al., 1972). Samter and Beers (1967) also failed to discover any difference in the handling of aspirin by various test systems between aspirinsensitive patients and normal controls. The same authors suggested that the cause of aspirin intolerance lies in an alteration by pre-existing disease of peripheral chemoreceptors (kinin receptors) through which aspirin initiated a series of axon reflexes ending in an asthma attack. According to our findings this hypothesis seems untenable.

Yurchak et al. (1970) suggested that aspirin might activate directly either complement components, with subsequent release of anaphylotoxins, or hypothetical tissue enzymes. In both situations there would be release of chemical mediators. No differences were found between levels of total haemolytic complement and components $\mathrm{C} 4$ and $\mathrm{C} 3$ in patients with aspirin sensitivity and normal controls (Delaney and Kay, 1976) but these measurements were not made during aspirin-induced bronchoconstriction.

Settipane et al. (1974) suggested that in certain asthmatics an abnormal mechanism may exist whereby aspirin blocks the release of $\mathrm{PGE}_{2}$, a bronchodilator, without blocking the release of the bronchoconstrictor $\mathrm{PGF}_{2} a$. Since sodium cromoglycate does not inhibit the peripheral action of $\mathrm{PGF}_{2} a$ this hypothesis seems unlikely.

Recently Szczeklik et al. (1975) have suggested that $\frac{D}{0}$ intolerance to aspirin and other analgesics is closely related to the inhibition of prostaglandin bio- N synthesis by these drugs. They speculate that, in $N$ asthmatic patients not sensitive to aspirin, endo- N genous histamine is balanced by the $\beta$-adrenergic $\omega$ system while the role of prostaglandins is less important. On the other hand, in aspirin-sensitive $\mathscr{C}$ patients the role of PGE in balancing the bronchoconstrictor effects of histamine and $\mathrm{PGF}_{2} a$ is more important than that of the $\beta$-adrenergic system. This inhibition of $\mathrm{PGE}_{2}$ 'disturbs the modulatory $\underset{\mathbb{D}}{\mathbb{D}}$ mechanism regulating bronchial tone, enhances the $\frac{?}{\mathbb{Q}}$ release of histamine from its stores, and enables $\varrho$ broncho-constriction to take place' (Szczeklik and ${ }^{\circ}$ Czerniawska-Mysik, 1976). These authors have 
shown that the ability of certain drugs to induce asthma attacks in aspirin-sensitive patients is roughly parallel to their power to inhibit prostaglandin biosynthesis in vitro (Szczeklik et al., 1975). Perhaps it is the reduction of both $\mathrm{PGE}_{1}$ and $\mathrm{PGF}_{2} a$ which is responsible for the syndrome because their low concentrations reduce cylic AMP levels and enhance mediator release (Kaliner and Austen, 1975).

We feel that challenge with aspirin is a safe procedure, even in highly sensitised patients such as ours, provided that challenge is started with doses of 5 to $10 \mathrm{mg}$ under close medical supervision. It must be borne in mind that aspirin hypersensitivity in these patients is not the cause of the disease because in most of them respiratory symptoms precede the onset of intolerance to aspirin, and careful avoidance of offending drugs does not alter the natural course of the disease (Samter and Beers, 1967). It is not surprising then that sodium cromoglycate did not have a therapeutic effect in a double-blind crossover study in patients with asthma and aspirin hypersensitivity (Gwin et al., 1974). Nevertheless there would seem to be a place for it after the start of an asthmatic attack due to aspirin or, if the patient realised that he had taken a dose of aspirin by mistake, sodium cromoglycate could be used in a prophylactic fashion.

We are particularly grateful to the patients participating in this study for their patience and cooperation. Thanks are due to Mrs. J. E. M. Durañona for typing the manuscript.

\section{References}

Beaven, M. A. (1976). Histamine. (Part 1). New England Journal of Medicine, 294, 30-36.

Cox, J. S. G. (1971). Disodium cromoglycate. Mode of action and its possible relevance to the clinical use of the drug. British Journal of Diseases of the Chest, 65, 189-204.

Cox, J. S. G., and Altounyan, R. E. C. (1970). Nature and modes of action of disodium cromoglycate (LOMUDAL). Respiration, 27, Supplement, 292-309.

Davies, S. E. (1968). Effect of disodium cromoglycate on exercise-induced asthma. British Medical Journal, 3, 593-594.

Delaney, J. C., and Kay, A. B. (1976). Complement components and IgE in patients with asthma and aspirin idiosyncrasy. Thorax, 31, 425-427.

Foreman, J. C., and Garland, L. G. (1976). Cromoglycate and other antiallergic drugs: a possible mechanism of action. British Medical Journal, 1, 820-821.

Girard, J. P., Hildebrandt, F., and Favre, H. (1969). Hypersensitivity to aspirin: clinical and immunological studies. Helvetia Medica Acta, 35, 86-95.

Gwin, E., Kerby, G., Hollinger, L. A., and Ruth, W. (1974). Cromolyn sodium in the treatment of asthma with aspirin hypersensitivity. (Abstract). Chest, 66, 325.
Kaliner, M., and Austen, K. F. (1975). Immunologic release of chemical mediators from human tissues. Annual Review of Pharmacology, 15, 177-189.

Kang, B., Townley, R. G., Lee, C. K., and Kolotkin, B. M. (1976). Bronchial reactivity to histamine before and after sodium cromoglycate in bronchial asthma. British Medical Journal, 1, 867-870.

Kolotkin, B. M., Lee, C. K., and Townley, R. G. (1974). Duration and specificity of sodium cromolyn on allergen inhalation challenges in asthmatics. Journal of Allergy and Clinical Immunology, 53, 288-297.

Lavin, N., Rachelefsky, G. S., and Kaplan, S. A. (1976). An action of disodium cromoglycate: inhibition of cyclic 3', 5', AMP phosphodiesterase. Journal of Allergy and Clinical Immunology, 57, 80-88.

Levy, G. (1965). Pharmacokinetics of salicylate elimination in man. Journal of Pharmaceutical Sciences, 54, 959-967.

McDonald, J. R., Mathison, D. A., and Stevenson, D. D. (1972). Aspirin intolerance in asthma: detection by oral challenge. Journal of Allergy and Clinical Immunology, 50, 198-207.

Patel, K. R. (1975). Atropine, sodium cromoglycate, and thymoxamine in $\mathrm{PGF}_{2} \alpha$-induced bronchoconstriction in extrinsic asthma. British Medical Journal, 2, 360-362.

Pepys, J., and Hutchcroft, B. J. (1975). Bronchial provocation tests in etiologic diagnosis and analysis of asthma. American Review of Respiratory Disease, 112, 829-859.

Roncorni, A. J., Goldman, E., Puy, R. J. M., and Mancino, M. (1975). Bronchoconstriction induced by repeated forced vital capacity manouvers. Acta Allergologica, 30, 375-389.

Rowland, M., Riegelman, S., Harris, P. A., and Sholkoff, S. D. (1972). Absorption kinetics of aspirin in man following oral administration of an aqueous solution. Journal of Pharmaceutical Sciences, 61, 379-385.

Samter, M., and Beers, R. F., Jr. (1967). Concerning the nature of intolerance to aspirin. Journal of Allergy, 40, 281-293.

Samter, M., and Beers, R. F., Jr. (1968). Intolerance to aspirin: clinical studies and consideration of its pathogenesis. Annals of Internal Medicine, 68, 975-983.

Schlumberger, H. D., Löbbecke, E. A., and Kallós, P. (1974). Acetylsalicylic acid intolerance. Acta Medica Scandinavica, 196, 451-458.

Settipane, G. A., Chafee, F. H., and Klein, D. E. (1974). Aspirin intolerance: 2 . A prospective study in an atopic and normal population. Journal of Allergy and Clinical Immunology, 53, 200-204.

Smith, A. P. (1971). Response of aspirin-allergic patients to challenge by some analgesics in common use. British Medical Journal, 2, 494-496.

Szczeklik, A., and Czerniawska-Mysik, G. (1976). Prostaglandins and aspirin-induced asthma. (Letter). Lancet, 1, 488.

Szczeklik, A., Gryglewski, R. J., and Czerniawska-Mysik, G. (1975). Relationship of inhibition of prostaglandin biosynthesis by analgesics to asthma attacks in aspirinsensitive patients. British Medical Journal, 1, 67-69.

Vatanasuk, M., Hornbrook, M. M., and Kohler, P. F. (1971). Serum IgE and passive transfer in aspirin intolerance. (Abstract). Journal of Allergy, 47, 109. 
Yurchak, A. M., Wicher, K., and Arbesman, C. E. (1970). Immunologic studies on aspirin: clinical studies with aspiryl-protein conjugates. Journal of Allergy, 46, 245-253.
Requests for reprints to: Dr. N. A. Martelli, Centro de Rehabilitacion. Respiratoria 'Maria Ferrer', Finochietto 849, Buenos Aires, Argentina 1272. 